\title{
Posebnosti sklanjatve samostalnikov $v$ prleškem narečju panonske narečne skupine na primeru govora vasi Cven
}

\section{Particularities of Noun Inflections in the Prlekija Dialect (the Pannonian Dialect Group)-an Example of Speech in the Village of Cven}

\author{
Mateja Kosi \\ (Ljubljana, Slovenija)
}

\begin{abstract}
:
Based on the example of speech in the village of Cven, the article discusses the particularities of noun inflections in the Prlekija dialect (the Pannonian dialect group) with a synchronic morphophonemic and morphological analysis. All three genders, all the numbers and all the cases have been preserved. The strong morphology-dependent stress contributes to the predominance of the fixed stem-stress paradigm, although nouns are still inflected according to the mobile stem-stress and mixed stem-stress paradigms. The dual, which is slowly disappearing from certain Slovenian dialects, has been strongly preserved. With certain nouns, the feminisation of neuter occurs (mostly with a singular number).
\end{abstract}

\section{Key words:}

dialectology; the Pannonian dialect group; the Prlekija dialect; morphology; morphophonology; noun

\section{Povzetek:}

V članku so na primeru govora vasi Cven kot dela ljutomerskega govora prleškega narečja panonske narečne skupine $\mathrm{v}$ sinhrono zasnovani oblikoslovni in oblikoglasni analizi predstavljene posebnosti sklanjatev samostalnikov v razmerju do slovenskega knjižnega jezika. Ohranjeni so vsi trije spoli, vsa števila in vsi skloni. Zaradi močne 
morfologizacije naglasa prevladuje nepremični naglasni tip, se pa samostalniki delno še sklanjajo po premičnem in mešanem naglasnem tipu. Dvojina, ki v mnogih narečjih slovenskega jezika počasi izumira, je še dobro ohranjena. Pri nekaterih samostalnikih prihaja do feminizacije nevter, najpogosteje v ednini.

\section{Ključne besede:}

dialektologija; panonska narečna skupina; prleško narečje; oblikoslovje; oblikoglasje; samostalnik

Posebnosti sklanjatev samostalnika so obravnavane na primeru govora vasi Cven kot dela ljutomerskega govora, ki spada v prleško narečje panonske narečne skupine. Sistem zagotovo velja za več prleških krajevnih govorov Murskega polja, predvsem za naslednje krajevne skupnosti: KS Cven, KS Ljutomer, KS Stročja vas in KS Krištanci, Šalinci, Grlava. Prleško narečje obsega govore po JV delu Slovenskih goric J od meje s slovenskogoriškim narečjem do meje s Hrvaško, poleg tega pa še po Dravskem polju med Zlatoličjem, Račami, Pragerskim, Majšperkom in Sv. Jurijem ob Ščavnici. Vzhodna meja prleškega narečja je reka Mura. Ime je narečje dobilo po pokrajini Prlekiji.

Zastopniki psl. staroakutiranih dolgih in novoakutiranih kratkih samoglasnikov ter umično naglašenih $\partial$, $e$, o so v govoru večinoma še kratki, podaljšali so se le v nekaterih enozložnicah. Sistem dolgih naglašenih samoglasnikov obsega 10 fonemov: $i: \ddot{u}, u$ : $\dot{e}$;,

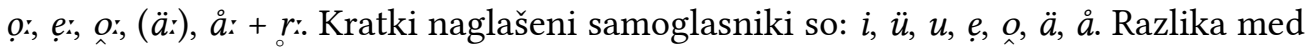
$r:$ in $r$ ni več zaznavna. Nenaglašeni samoglasniki so samo kratki: $i, u, o, \ddot{a}, \stackrel{a}{a}+r, l, n$. Soglasniški sistem obsega zvočnike $m, n, v, l, r, j$ ter nezvočnike $p, b, t, d, k, g, x, f, s, z$, $\check{s}, \check{z}, c$ in $\check{c}$. Naglas je dinamični in ni vezan na določeno mesto $\mathrm{v}$ besedi.

\section{OBLIKOSLOVNA IN OBLIKOGLASNA KLASIFIKACIJA SAMOSTALNIKA V GOVORU VASI CVEN}

\section{Sklanjatve samostalnikov moškega spola}

\subsection{Prva moška sklanjatev}

V prvo moško sklanjatev se poleg samostalnikov, ki imajo v I ed. končnico - ø, v R ed. pa $-a$ ali $-a ́$, nar. $-a ̊ a$ ali -o्र:, uvrščajo tudi samostalniki moškega spola z imenovalniškimi končnicami $-a$, nar. $-\stackrel{a}{a}$ ('Mixå), med katere so prešli tudi samostalniki moškega spola s končnico -e, nar. -å (óčcåa, 'fožåa).

Samostalniki moškega spola se sklanjajo večinoma po nepremičnem naglasnem tipu, precej dobro je ohranjen tudi premični naglasni tip, slabše pa mešani in končniški naglasni tip. 


\section{Nepremični naglasni tip}

\begin{tabular}{|c|c|c|c|c|c|c|}
\hline & I & $\mathrm{R}$ & $\mathrm{D}$ & $\mathrm{T}$ & M & $\mathrm{O}$ \\
\hline ed. & x'ro:st & x'rọ:stå & x'ro:sti & x'ro:st & pr x'ro:sti & s x'rox:stọn \\
\hline dv. & x'ro:stå & x'roxstọf & x'rôx:stọmå & x'ro:stå & pr x'ro:stix & s x'rôx:stọmå \\
\hline $\mathrm{mn}$. & x'ro:sti & x'ro:stọf & x'ro:stọn & x'ro:stä & pr x'ro:stix & s x'ro:sti \\
\hline
\end{tabular}

Tako se sklanja še večina samostalnikov m. sp. (pri nekaterih sam. zaradi kakovostne in kolikostne spremembe dodajam R mn.): 'åtäk 'åtäkå 'atek, oče', b'ro:č 'obiralec grozdja, trgač', 'cäjt 'čas', 'cukär 'cukrå 'sladkor', 'čäp, 'dèll, g'lå:š g'låžåa 'steklenica', g'rost g'rozdå, xi'di:č 'hudič', g'vixt 'utež', klin'tọ:n 'vrsta trte', 'Pr:läk 'Pr:läkå, 'pü:tår 'pü:tårå 'brentar', rộčäj, š'toplol 'zamašek', 'žåkäl 'žåklå 'žakelj' idr.

Pri nepremičnem naglasnem tipu na osnovi je lahko naglašen samoglasnik v edinem zlogu (šllåx 'natega', 'tr:s) ali kateremkoli zlogu v večzložni besedi ('žåäal, rä'mė:näc rä'mè:ncå 'trak iz blaga', pọlov'jo:k 'sod').

V govoru nepremični naglasni tip prevladuje, saj so vanj prešli tudi nekateri samostalniki, ki se v knjižnem jeziku sklanjajo po drugih naglasnih tipih, npr.:

- iz premičnega naglasnega tipa sôsed soséda ('sọ:sit 'sọ:sidå, pälli:n päli:nå);

- iz mešanega naglasnega tipa sín sinú sinôvi, ker govor ne pozna naglašene ujevske končnice v R ed. in daljšanja osnov z -ov- v mn. (g'ro:di, 'mọ:sti, 'nọ:si, 'vọ:zi). Na primer: 'si:n, 'si:nå, 'si:ni, 'si:nå, pr 'si:ni, s si:nọn;

- iz končniškega naglasnega tipa dèž dežjà in pekèl peklà, ker govor pozna umik naglasa z vsake končne kračine in posplošitev osnove ('dä:š 'däžå, 'päkäl 'päklå).

\section{Premični naglasni tip}

Govor pozna samo premični naglas na osnovi tipa mêdved medvéda (torej v vseh številih in z izjemami zgoraj), ne pa gròb grôba grobôvi.

\begin{tabular}{lllllll}
\hline & $\mathrm{I}$ & $\mathrm{R}$ & $\mathrm{D}$ & $\mathrm{T}$ & $\mathrm{M}$ & $\mathrm{O}$ \\
\hline ed. & 'jäzik & jä'zikå & jä'ziki & 'jäzik & pr jäziki & z jä'zikọn \\
\hline $\mathrm{dv}$. & jä'zikå & jä'zikọf & jä'zikọmå & jä'zikå & pr jä'zikio & z jä'zikọmå \\
\hline mn. & jä'ziki & jä'zikọf & jä'zikọn & jä'zikä & pr jä'zikị & z jä'ziki \\
\hline
\end{tabular}

Tako tudi: 'bätäk bä'tägå 'bolezen', 'mädvit mäd'vẹdå 'medved', 'orix ớrexå 'oreh' idr. 
V premični naglasni tip se po umiku naglasa s končnega kratkega zloga uvrščajo tudi samostalniki, ki so v knjižnem jeziku v nepremičnem naglasnem tipu, npr. 'potplåt, pọtplåtå. Tako se sklanjajo še: 'cigån ci'gọ:nå, 'muškåt muškkåtå, 'otrọk ọtrokåa.

\section{Mešani naglasni tip}

Mešani naglasni tip je redek, saj pogosto prehaja v nepremičnega. Kljub temu se nekaj enozložnih samostalnikov z izhodiščnim dolgim samoglasnikom v I ed. in končnico $-a \mathrm{v}$ R ed. dvojnično še sklanja po mešanem naglasnem tipu. Primer: 'bọ:k, bọ'go:/ /'bogå, 'bọ:gi/'bogi, bọ́go:/'bogå, pr 'bo:gi/pri 'bogi, z 'bọ:gonn/z 'bogon. Tako še: v'rå:g vrå'go:/ v'rå:gå, s'nè:k snä'gọ:/s'nè:gå.

V mešani naglasni tip sta iz končniškega prešla samostalnika låsjjẹ: in zobjjẹ:, kot dvojnično tudi samostalnik lid'je: 'ljudje'. Prim. lås'jẹ:, 'lo:sis, låsẹ:n, lå'sẹ:, v låsẹ:x, z lås'mi:

\section{Končniški naglasni tip}

Samostalniki, ki se v knjižnem jeziku sklanjajo po končniškem naglasnem tipu, se $\mathrm{v}$ govoru uvrščajo v nepremični naglasni tip na osnovi.

V množini imajo kot dvojnično naglašeno končnico -je, nar. -'jẹ: in vse nadaljnje oblike le samostalnik lid'jẹ: 'ljudje', medtem ko sta samostalnika lås'jẹ: in zọbjẹ: zaradi oblike R mn. prešla v mešani naglasni tip. Primer: lidjje:, 'lü:di/li'di:, li'dè:n, li'di:, o li'dèxx, z lid'mi:

\subsection{Druga moška sklanjatev}

Druge moške sklanjatve v govoru ni, saj se samostalniki, ki zaznamujejo moške osebe in imajo v imenovalniku končnico -å ('Mixå), ne sklanjajo po ženski a-jevski sklanjatvi, ampak po 1. moški sklanjatvi (sam. m. sp.).

\subsection{Tretja moška sklanjatev}

Tretje moške sklanjatve govor ne pozna, saj se noben samostalnik ne sklanja z ničto končnico v vseh sklonih. Rabljene kratice (npr. $B M W$ ) se sklanjajo po prvi moški sklanjatvi ('bẹm've:jå, 'bẹm'vẹji $\ldots$...).

\section{4 Četrta moška sklanjatev}

$\mathrm{V}$ četrto moško sklanjatev spadajo posamostaljeni pridevniki moškega spola: d'rü:gi 'drugi', m'lo:di 'mladi', s'to:ri 'stari', 'vẹ:ki 'veliki'. Sklanjajo se npr.: s'torri, s'to:rägå, s'to:rämo, s'to:rägå, pr s'to:rän, s s'to:rin. 


\section{Sklanjatve samostalnikov ženskega spola}

\subsection{Prva ženska sklanjatev}

Po prvi ženski sklanjatvi se v govoru sklanja večina sam. ž. sp., ki imajo v I ed. končnico $-a$, nar. $-a ̊$, v R pa $-e$, nar. $-\ddot{a}$.

Najpogostejši je nepremični naglasni tip, $v$ redkih primerih je ohranjen tudi mešani naglasni tip, končniški naglasni tip ima samo samostalnik gospa.

\section{Nepremični naglasni tip}

\begin{tabular}{lllllll}
\hline & I & R & D & T & M & O \\
\hline ed. & k'råvå & k'råvä & k'råvi & k'råvọ & pr k'råvi & s k'råvọj \\
\hline dv. & k'råvi & k'ro:f & k'råvåmå & k'råvi & pr k'råvåx & s k'råvåmå \\
\hline mn. & k'råvä & k'ro:f & k'råvån & k'råvä & pr k'råvåx & s k'råvåmi \\
\hline
\end{tabular}

Tako se sklanjajo še (pri nekaterih sam. zaradi kakovostne in kolikostne spremembe dodajam R mn.): b'rä:jdå b'rojd 'brajda', 'ju:rkå 'vrsta trte', *'košjå 'košän, 'kurpå 'pletena košara', "'mẹ:zdrå 'mẹ:zdär 'smetana na mleku', *'mätlå 'mätäl, 'mọ:jngå 'mọ:jnk 'škripec', 'påvočinå 'pajčevina', povioticå 'potica', 'vo:gå 'tehtnica', 'žågå idr.

*Če se osnova samostalnika končuje na soglasniški sklop nezvočnika in zvočnika, se $\mathrm{v} d \mathrm{v}$. in v mn. pred zvočnik vriva ä (za knjižni polglasnik) 'mẹ:zdrå 'mẹ:zdär 'smetana na mleku', 'mätlå 'mätäl.

Tako se sklanjajo tudi samostalniki ženskega spola na -ev, nar. na -vå, npr. b'ro:två 'trgatev', 'bükvå 'bukev', b'rẹskvå, 'cèrkvå, 'žẹtvå, vendar pa 'tikäf 'buča', p'le:täf.

Po nepremičnem naglasnem tipu se sklanjajo tudi:

- nekateri samostalniki, ki se v knjižnem jeziku sklanjajo po mešanem naglasnem tipu (žêna žené), so zaradi morfologizacije naglasa, tj. posplošitve naglasa osnovne oblike, prešli v nepremični naglasni tip, npr 'žänå, 'žänä, medtem ko se nekateri še vedno sklanjajo po mešanem naglasnem tipu, npr. 'vodå, vọ́dẹ: Tako še: 'nọ:gå.

- po nepremičnem naglasnem tipu se sklanjajo tudi samostalniki iz končniškega naglasnega tipa stezä stezë/-ẹ, saj se je naglas s kratkega končnega zloga umaknil na prednaglasni kratki samoglasnik, ki se še ni podaljšal, npr. 'mäglå, 'mäglä. Tako še: 'däskå 'däskä, 'tämå 'tämä.

- zaradi feminizacije se nekateri samostalniki srednjega spola sklanjajo po ženski sklanjatvi ('bädrå 'stegno', 'jåbọkå, 'ọ:kå, 'rẹ:brå), vendar ne nujno v vseh številih bolj pogosto $\mathrm{v}$ ednini kot $\mathrm{v}$ dvojini in množini. Tem so se pridružili tudi nekateri samostalniki, ki so doživeli umik cirkumflektiranega naglasa z zadnjega zloga ('pä:rå 
'pero', 'ọ:kå, 'vü:xå 'uho', d'rė:vå); po prehodu v žensko sklanjatev osnove s -s- ne daljšajo.

\begin{tabular}{lllllll}
\hline & $\mathrm{I}$ & $\mathrm{R}$ & $\mathrm{D}$ & $\mathrm{T}$ & $\mathrm{M}$ & $\mathrm{O}$ \\
\hline ed. & 'pä:rå & 'pä:rä & 'pä:ri & 'pä:rọ & pri pärri & s pä:rọj \\
\hline dv. & 'pä:ri & 'pä:r & 'pä:råmå & 'pä:ri & pri 'pä:råx & s pä:råmå \\
\hline mn. & 'pä:rä & 'pä:r & 'pärån & 'pä:rä & pri 'pä:råx & s pä:råmi \\
\hline
\end{tabular}

Tako še d'rè:vå, 'ọ:kå, 'vü:xå.

\section{Mešani naglasni tip}

Nekateri samostalniki - natančneje 'nọ:gå in 'vodå -, ki se v knjižnem jeziku sklanjajo po mešanem naglasnem tipu in so večinoma prešli v nepremični naglasni tip na osnovi, se v ednini dvojnično sklanjajo tudi po mešanem naglasnem tipu: 'vodå, vọ'dẹ:, 'vodi, vọ́dọ:, nå vodi, z vọ́dọj. Tako še: 'nọ:gå.

Posebna je sklanjatev samostalnika mati: 'måti, måtä'rė:, 'måtäri, måtä'rẹ:, pr 'måtäri, $z$ 'mo:tärjoj.

\section{Končniški naglasni tip}

Ima ga iz knjižnega jezika prevzeti samostalnik gos'pa:, ki se sklanja kot v knjižnem jeziku brez narečnih glasovnih prilagoditev.

\subsection{Druga ženska sklanjatev}

Po tej sklanjatvi se sklanjajo sam. ž. sp., ki imajo v I ed. končnico - $\emptyset$, v R ed. pa končnico $-i$ oz. $-i$, nar. $-i$ oz. - $i$. Druga ženska sklanjatev se oblikovno ne razlikuje od knjižne, le v nepremičnem naglasnem tipu ima končnico O ed. -oj.

Samostalniki te sklanjatve se uvrščajo v nepremični in mešani naglasni tip.

\section{Nepremični naglasni tip}

\begin{tabular}{lllllll}
\hline & $\mathrm{I}$ & $\mathrm{R}$ & $\mathrm{D}$ & $\mathrm{T}$ & $\mathrm{M}$ & $\mathrm{O}$ \\
\hline ed. & 'nit & 'niti & 'niti & 'nit & pr 'niti & $\mathrm{z}$ 'nitjọj \\
\hline $\mathrm{dv}$. & 'nitio & 'niti & 'nitimå & 'niti & pr 'nitix & z 'nitimå \\
\hline mn. & 'niti & 'niti & 'nitio & 'niti & pr 'nitix & $\mathrm{z}$ 'nitmi \\
\hline
\end{tabular}


Tako se sklanjajo še: bọ'lẹ:zän bọ'lẹ:zni, ọ'lüp 'lupina', pärọ:t 'perut', plessän p'lesni.

\section{Mešani naglasni tip}

Druga ženska sklanjatev je ohranila mešani naglasni tip z ijevskimi končnicami ('kọ:st kọs'ti:). V tem naglasnem tipu so končnice oblikovno enake knjižnim. Po mešanem naglasnem tipu pa se v drugi ženski sklanjatvi sklanjajo enozložni sam., ki imajo v I ed. končnico $-\varnothing$, v R pa ed. in I mn. pa naglašeni -í, npr. 'nọ:č.

\begin{tabular}{|c|c|c|c|c|c|c|}
\hline & I & $\mathrm{R}$ & $\mathrm{D}$ & $\mathrm{T}$ & M & $\mathrm{O}$ \\
\hline ed. & 'nọ:č & nọ'či: & 'nọ:či & 'nọ:č & v 'nọ:či & z nọčjọ:j \\
\hline dv. & 'nọ:či & nọ'či: & nọ'čẹmå & 'nọ:čí & v nọ'čẹ:x & z nọ'čẹmå \\
\hline mn. & nọ'či: & nọ̌či: & nọ'čẹ:n & nọ'či: & v nọ’čẹ:x & z nọčmi: \\
\hline
\end{tabular}

Tako se sklanjajo še: k'lè:t klätti:, 'kọ:st, 'mọ:č, 'sọ:l, st'vo:r stvåri: 'stvar', 'vẹ:s vå'si: 'vas'.

Po mešanem naglasnem tipu se sklanjata tudi samostalnik kri: 'kr:f, kr'vi:, 'kr:vi, 'kr:f,

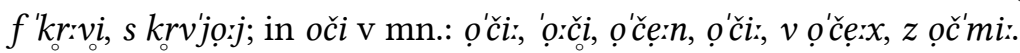

\subsection{Tretja ženska sklanjatev}

$\mathrm{S}$ končnico $-\varnothing \mathrm{v}$ vseh sklonih in številih se $\mathrm{v}$ govoru sklanja le malo samostalnikov ženskega spola. Med njimi je največ prevzetih ženskih imen - 'Kårmän, 'Inäs in ljubkovalnic - 'måmi (nov. prevzeto iz knjižnega jezika).

\section{4 Četrta ženska sklanjatev}

Posamostaljenih pridevniških besed ženskega spola je v govoru zelo malo, npr.: s'to:rå 'mati, žena, prijateljica', m'lo:då 'snaha, hči'; sklanjajo se kot pridevniška beseda, npr.: s'to:rå, s'to:rä, s'to:ri, s'to:ro, pr s'to:ri, s s'to:roj.

\section{Sklanjatve samostalnikov srednjega spola}

\subsection{Prva srednja sklanjatev}

Po tej sklanjatvi se sklanjajo sam. sr. sp., ki imajo v I ed. končnico -o, v R ed. pa - $a$ in se niso feminizirali. Sklanjajo se po nepremičnem, premičnem, mešanem in končniškem naglasnem tipu. 


\section{Nepremični naglasni tip}

\begin{tabular}{lllllll}
\hline & $\mathrm{I}$ & $\mathrm{R}$ & $\mathrm{D}$ & $\mathrm{T}$ & $\mathrm{M}$ & $\mathrm{O}$ \\
\hline ed. & 'oknọ & 'oknå & 'okni & 'oknọ & nå 'okni & z 'oknọn \\
\hline $\mathrm{dv}$. & 'okni & 'ọ:kän & 'oknọmå & 'okni & nå 'oknix & z 'oknọmå \\
\hline mn. & 'oknå & 'ọkkän & 'oknọn & 'oknå & nå 'oknio & z 'okni \\
\hline
\end{tabular}

Tako še: dọ'lo:gåjä 'dolaganje’, g'nèzzdo, g'rọ:zdjä, kộläno, ớrọjjä 'oranje', pät'li:čjä 'večja količina pecljev', 'rožjä 'večja količina rozg', 'suncä, škrọ'pi:vọ, 'zr:nọ, žrrälọ.

Sem spadajo tudi samoedninski samostalniki: b'låto, 'delo, m'le:kọ, 'vi:no, 'vo:pno 'apno', žällęzo, 'žitọ 'rž. Tako se sklanjajo tudi samomnožinski samostalniki - 'dr:vå, d'vẹ:rcå 'vratca', g'rẹ:då, 'jẹ:trå, 'kọ:lå 'voz', p'lü:čå 'pljuča'. Po tem vzorcu se od R dalje sklanjajo še samoedninski samostalniki na -ovje, nar. 'ọvvjä, ki so v govoru kar pogosti: vät'rọ:vjä 'več vetrov', brä'gọ:vjä 'več bregov' itd.

Sam. vime podaljšuje osnovo $\mathrm{z}-n$-, sklanja pa se po nepremičnem naglasnem tipu 'vimä 'vimänå. Sam. žrebe podaljšuje osnovo s $-t$-, sklanja pa se po nepremičnem naglasnem tipu žr $r$ bẹ:, žr r'bätå. Podaljšave s -s- govor ne pozna.

Zaradi feminizacije nevter so nekateri sam. sr. sp. v vseh številih prešli v ž. sp.: 'pärrå 'pero', 'jåbọkå, 'råmå itd. Pri nekaterih primerih se oblika in s tem sklanjatev za srednji spol ohranja poleg ženske: 'oknål' okno, d'rè:våld'ré:vọ, 'vü:xal'vü:xọ 'uho'. Samostalnik jäjcå se je feminiziral v ed. in dv., v mn. pa se deloma sklanja po srednji sklanjatvi.

\section{Premični naglasni tip}

Tako se sklanja nekaj sam. sr. sp., ki v sklanjatvi podaljšujejo osnovo z $-n$ - ali s $-t$ -

\begin{tabular}{lllllll}
\hline & $\mathrm{I}$ & $\mathrm{R}$ & $\mathrm{D}$ & $\mathrm{T}$ & $\mathrm{M}$ & $\mathrm{O}$ \\
\hline ed. & 'sämän & sä'mänå & sä'mäni & 'sämän & $\mathrm{f}$ sä'mäni & s sä'mänọn \\
\hline $\mathrm{dv}$. & sä'mäni & sä'män & sä'mänọmå & sä'mäni & f sä'mänio & s sä'mänọmå \\
\hline mn. & sä'mänå & sä'män & sä'mänọn & sä'mänå & f sä'mänio & s sä'mäni \\
\hline
\end{tabular}

Tako še: v'rė:män vrä'mänå; 'dè:tä di'tätå, 'piščä pišščätå. 


\section{Mešani naglasni tip}

Po njem se sklanjajo sam. sr. sp., ki se v I ed. končujejo na naglašeni končnici -o, nar. $-o$; in -e, nar. -ẹ: Naglas na končnici imajo v I, R in T ed. Večina teh samostalnikov pozna le edninske oblike. Primer: blågọ:, blågo:, b'lo:gi, blå'go:, nå b'lo:gi, z b'lo:gọn. Tako še: sr'cẹ:, zlåtọ:

Posebnost so samostalniki, ki imajo v R, D, M in O naglas na osnovi: mä'sọ:, 'mẹ:så, 'mẹ:si, mä'so:, v 'mẹssi, z 'mẹ:sọn. Tako še: si'nọ: 'sė:nå 'seno', näbọ: 'nė:bå, črä'vọ: čré:vå.

\section{Končniški naglasni tip}

Sem spadajo nekateri samoedninski samostalniki, ki imajo v I mn. končnico -'jẹ:, npr.

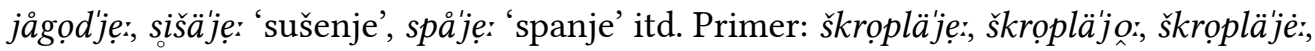
škrọpläjjẹ:, v škrọpläjej:, s škrọpläjọ:n.

\subsection{Druga srednja sklanjatev}

Druge srednje sklanjatve ni.

\subsection{Tretja srednja sklanjatev}

V tretjo srednjo sklanjatev sodita samostalnika 'jesti ' 'hrana' in 'piti 'pijača'.

\section{4 Četrta srednja sklanjatev}

Po četrti srednji sklanjatvi se sklanjajo redki posamostaljeni pridevniki in nekaj krajevnih imen, npr. 'Šåfårskọ, 'Šååarskägå, 'Šååarskämo, 'Šååarsko, nå 'Šååarskän, s'Šåfårskin.

\section{Sklep}

V govoru vasi Cven so pri samostalniku ohranjeni vsi trije spoli, vsa števila in vsi skloni. Zaradi močne morfologizacije naglasa prevladuje nepremični naglasni tip, se pa samostalniki delno še sklanjajo po premičnem in mešanem naglasnem tipu, redko je ohranjen končniški tip.

\section{a) Samostalniki moškega spola}

Samostalniki moškega spola se sklanjajo večinoma po nepremičnem naglasnem tipu, precej dobro je ohranjen tudi premični naglasni tip, slabše pa mešani in končniški naglasni tip. Govor samo pri nekaterih samostalnikih ohranja premični naglas na osnovi tipa mêdved medvéda (torej v vseh številih), ne pa gròb grôba grobôvi, zato 
v samostalnikih tipa b'rè:k b'rè:gå, 'du:k 'du:gå 'dolg' ni kolikostnih in kakovostnih premen.

V D in M ed. imajo sam. m. sp. končnico -i, npr. 'åtäki 'ateku', $k$ 'sọssidi 'k sosedu'. Za govorjenim $c, j, \check{c}, \check{z}, \check{s}$ ali $d \check{z}$ v O ed. ni preglasa, npr. s st'ri:con, $z_{\circ}$ ig'riščcon; enako ni preglasa $-o \mathrm{v}-e \mathrm{v} \mathrm{R} d \mathrm{v}$. in mn., v D in O dv. ter v D mn., npr. st'riccof, st'ri:comå, st'ri:con. Odvisni skloni pri samostalnikih, ki se končujejo na - $r$, ne podaljšujejo osnove z $-j$, npr. kọ'lèrr kọ'lè:rå 'ovratnik'. Izpolglasniški e pri sklanjatvi ne izpade vedno - predvsem ne v besedah, ki pomenijo pomanjševalnice, npr. 'gujdäk 'gujdäkå 'prašič', 'vozäk 'vozäkå 'voziček'; toda: 'cukär 'cukrå 'sladkor', 'kåmän 'kåmnå. Nekateri samostalniki imajo v I mn. končnico -jä ali -jẹ:, npr. zob'je:, k'mätjä. Samostalnika las in zob imata v R mn. končnico -i, npr. 'zọ:bi, 'lo:si. Krajevna imena na -ci tipa K'rižofcise sklanjajo iz K'rižoväc (R mn.), toda v K'rižofcix (M mn.).

\section{b) Samostalniki ženskega spola}

Najpogostejši je nepremični naglasni tip, $v$ redkih primerih je ohranjen tudi mešani naglasni tip, končniški naglasni tip ima samo samostalnik gospa.

V D mn. se uporablja končnica -ån < -am zaradi glasovnega razvoja $-m>-n$. $\mathrm{V} O$ ed. se končnici -o pridaja $-j$, dobimo -oj. Če se osnova samostalnika končuje na soglasniški sklop nezvočnika in zvočnika, se v dv. in v mn. pred -ø vriva polglasnik 'lü:kjå 'lü:kän 'luknja', 'mätlå 'mätäl. Narečno se končnica samostalnikov ženskega spola na -ev glasi -vå, npr. b'ro:två 'trgatev', 'bükvå 'bukev', b'rẹskvå, 'cé:rkvå, vendar pa 'tikäf 'buča', p'le:täf. Do kolikostne in kakovostne premene naglašenega samoglasnika prihaja v R mn. v edinem zlogu: b'rä:jdå b'rojd 'brajda', k'råvå k'ro:f, 'oså 'ọs, 'vürä 'vü:r 'ura', 'žämlå 'žèmmäl ‘žemlja'.

Zaradi feminizacije se nekateri samostalniki srednjega spola sklanjajo po ženski sklanjatvi ('bädrå 'stegno', 'jåbọkå, 'ọ:kå, 'rẹ:brå; 'pä:rå 'pero', 'ọ:kå, 'vü:xå 'uho', d'rè:vå); po prehodu v žensko sklanjatev osnove s -s-ne daljšajo. Samostalnik mati od R ed. dalje svojo osnovo podaljšuje z -er-, sklanja se po mešanem naglasnem tipu. Samostalnik $k r i$ ima enako osnovo kot v odvisnih sklonih tudi v I in T ('krf kr'vi:).

\section{c) Samostalniki srednjega spola}

Sklanjajo se po nepremičnem, premičnem, mešanem in končniškem naglasnem tipu.

Zaradi feminizacije nevter so nekateri sam. sr. sp. v vseh številih prešli v ž. sp.: 'pärrå 'pero', 'jåbọkå, 'råmå itd. Pri nekaterih primerih se oblika in s tem sklanjatev za srednji spol ohranja poleg ženske: 'oknål'okno, d'ré:våld'ré:vọ, 'vü:xa/'vü:xọ 'uho'. Samostalnik 'jäjcå se je feminiziral v ed. in dv., v mn. pa se deloma sklanja po srednji sklanjatvi.

Končnica $\mathrm{v} \mathrm{D}$ in $\mathrm{M}$ ed. je $-i<-u$. Končnica $\mathrm{D}$ mn. -ọn <-ọm. Za govorjenim $c, j, \check{c}, \check{z}$, $\check{s}$ se v O ed. rabi nepreglašena končnica -ọn < -om, npr. $z$ 'ọljọn, s 'sr:cọn, z gråd'biščon. 
Enako ni preglasa -o v -e v D in O dv. ter v D mn., npr. 'srrccomå, s 'srrcomå, 'sr:cọn. Podaljšanje osnove $s-t$ in $-n$ je prisotno, $s-s$ - pa samostalniki osnove ne podaljšujejo tudi v primeru, ko ostanejo srednjega spola: d'ré:vo d'rèvvå. Nekateri sam. sr. sp., ki se sklanjajo po premičnem naglasnem tipu in podaljšujejo osnovo $\mathrm{z}-n$ - od R dalje, jo v govoru posplošijo že v I ed., npr.: 'sämän, v'ré:män. Vrivanje polglasnika, nar. -ä, v soglasniški sklop nezvočnika in zvočnika v R dv. in mn. je prisotno 'je:trå 'je:tär, 'pismå 'pi:säm. Posebna sklanjatev z naglasom na osnovi v R se pojavi pri nekaj samostalnikih srednjega spola, ki se sklanjajo po vzoru samostalnika meso (mä'sọ:, 'mẹ:så).

\section{Literatura:}

JAKOP, T.: Oblikoslovje govora Ložnice pri Žalcu. Magistrsko delo. Ljubljana: Filozofska fakulteta, 2001.

KOLETNIK, M.: Vinogradniška terminologija na Gomili pri Kogu. In: JESENŠEK, M. VRBNJAK, V. (eds): Borkov zbornik, (Zbirka Piramida). Maribor: Slavistično društvo, 1996, str. 91-104.

KOSI, M.: Prleški govori Murskega polja. Magistrsko delo. Ljubljana: Filozofska fakulteta, 2016.

SMOLE, V.: Oblikoglasje in oblikoslovje šentruperskega govora. Doktorsko delo. Ljubljana: Filozofska fakulteta, 1994 .

ZORKO, Z.: Spodnjeprleško narečje. Časopis za zgodovino in narodopisje, 2008, št. 1-2, str. $139-145$.

- -: Oblikoslovje v panonski narečni skupini. Slavia Centralis, 2010, št. 1, str. 5-17.

\section{About the author Mateja Kosi}

University of Ljubljana, Faculty of Arts, Department of Slovenian Studies, Ljubljana, Slovenija mateja.kosi@ff.uni-lj.si 
